\title{
Memórias de tempos sombrios
}

Regina Zilberman ${ }^{1}$

\section{Tempos sombrios}

Em Homens em tempos sombrios, Hanna Arendt justifica o título e o tema do livro destacando a atuação de "homens e mulheres" que ofereceram "alguma iluminação" em períodos "em que o âmbito público se obscureceu e o mundo se tornou tão dúbio que as pessoas deixaram de pedir qualquer coisa à política" (Arendt, 2008, p. 19), iluminação esta proveniente "menos das teorias e conceitos, e mais da luz incerta" de "suas vidas e obras", irradiando-se "pelo tempo que lhes foi dado na Terra" (Arendt, 2008, p. 9).

Lessing, Rosa Luxemburgo, Papa João XXIII, Karl Jaspers, Isak Dinesen, Walter Benjamin - eis algumas das pessoas que, segundo Arendt, iluminaram a vida e o pensamento ocidental em épocas nas quais, ainda que "os olhos" estivessem "habituados às sombras" (Arendt, 2008, p. 9), não se satisfizeram em "evita[r] os embates do mundo", como aconselha Bertolt Brecht no poema "À posteridade":

Gostaria de ser sábio.

Os livros antigos nos informam o que é sabedoria:

Evita os embates do mundo, vive tua curta vida

Sem temer ninguém

Sem recorrer à violência

Pagando o mal com o bem -

Não a satisfação do desejo mas o alheamento

Passa por sabedoria.

Eu não posso fazer nada disso:

Não há dúvida que vivo numa idade escura! (Brecht, 2011, s.p.).

Não é, contudo, apenas dos indivíduos que se elevaram em "tempos sombrios" que doravante se fala, mas daqueles que sofreram os efeitos da escuridão, bem como daqueles que se beneficiaram dela. Por isso, tomamos a liberdade de parafrasear, mas

${ }^{1}$ Doutora em letras, pesquisadora do CNPq e professora da Universidade Federal do Rio Grande do Sul (UFRGS), Porto Alegre, RS, Brasil. E-mail: reginaz@ portoweb.com.br 
também alterar, o título do livro de ensaios de Hanna Arendt, esperando que suas luzes ajudem a aclarar o trajeto.

\section{Quando o passado condena}

As emblemáticas imagens das derrubadas de monumentos dedicados a chefes de Estado e de ditadores do século XX, amplamente difundidas pela imprensa e pela Web, podem ser ajustadas para falar da queda do prestígio de intelectuais atuantes nas décadas finais do século XX. Na segunda metade dos anos 1980, foi revelado que Paul de Man, então incontestado representante do desconstrutivismo na América do Norte, tinha redigido artigos de conteúdo nazista para Le Soir, jornal belga dirigido por membros do exército alemão de ocupação. Já então se sabia que Martin Heidegger aderira ao Partido Nazista poucos dias depois de nomeado reitor da Universidade de Freiburg. Nos anos 1990, foi a vez de Hans Robert Jauss, voluntário das Waffen-SS alemãs - fato a respeito do qual o ilustre professor da Escola de Constança, até ser denunciado, nunca se referira, segundo o depoimento de Hans Ulrich Gumbrecht, seu aluno no começo dos anos 1970. Por seu turno, o ficcionista e ganhador de Prêmio Nobel de Literatura, Günther Grass, preferiu, ele mesmo, em Descascando a cebola, autobiografia datada de 2006, expor seus tempos de adepto do nazismo na juventude e membro das Waffen-SS.

Desses intelectuais e homens de influência no campo cultural, esperava-se mais de seu passado - ou de suas ações na juventude. Mas aquele passado não pode ser modificado, sobretudo depois de difundidas as ações que o comprometem. Pode-se eventualmente alterar a designação dada a ele, esforço permanente dos historiadores e que se traduz em outras iniciativas, algumas de ordem política. Quando, por exemplo, na cidade de Porto Alegre, confere-se o nome de Avenida da Legalidade à ex-Avenida Castelo Branco, o intuito não é de mudar os fatos, mas avaliá-los segundo paradigmas, em princípio, progressistas.

Porque essas são as questões que estão em jogo. Em primeiro lugar, como julgar os fatos pretéritos, tenhamos ou não feito parte dele? E como podemos nos posicionar diante dele, sobretudo quando seus efeitos, então e agora, incidem sobre nossas ações e exercício da profissão? 
Em um de seus provavelmente primeiros diálogos, Críton, Platão expõe uma situação que, de certo modo, encaminha respostas àquelas questões. O texto, que carrega o subtítulo "Do dever", tem composição dramática, pois a cena, formada por Críton e Sócrates, transcorre na cela - um espaço sombrio, como poderia qualificá-lo Hannah Arendt - em que Sócrates está aprisionado, na antevéspera de sua morte.

Acusado de corruptor da juventude, Sócrates fora julgado pela justiça ateniense e condenado ao suicídio por envenenamento. Críton, companheiro do filósofo desde a infância, prepara sua fuga: ajusta a cidade que o hospedará, as pessoas que, devidamente subornadas, o ajudarão a escapar da prisão, os guias que o conduzirão ao exílio. Sócrates está consciente de que, em dois dias, estará morto, mas recusa firmemente o socorro do velho amigo. Justifica a decisão, argumentando que, se assim o fizer, cometerá um ato ilegal, e ele não se permite ingressar na injustiça:

Sócrates - Logo, jamais se deve proceder contra a justiça.

Critão - Jamais, por certo.

Sócrates - Nem mesmo retribuir a injustiça com a injustiça, como pensa a multidão, pois o procedimento injusto é sempre inadmissível (Platão, s.d., 49b-49c).

Mais adiante, Sócrates cogita o que dirão os demais, se optar pela alternativa oferecida por Críton:

Quanto a ti, para começar, se partires para uma das cidades mais próximas - digamos Tebas ou Mégara, que ambas têm boas leis ali entrarás, Sócrates, como inimigo de suas instituições; todos quantos zelam por suas cidades te olharão de través, como um destruidor das leis; consolidarás a reputação de teus juízes, de sorte que pareçam haver-te julgado escorreitamente, porque todo violador das leis bem pode ser tido como corruptor dos jovens e dos levianos. Ou acaso evitarás as cidades de boas leis e os homens mais morigerados? E valerá a pena viveres com esse comportamento? Ou entrarás em contato com eles e discorrerás, sem acanhamento... sobre o quê, Sócrates? Sobre os teus assuntos daqui? Sobre o supremo valor que têm para a humanidade a virtude, a justiça, assim como a legalidade e as leis? E não achas que o papel de Sócrates se manifestará indecoroso? Tens de achar. Admitamos que, afastando-se desses lugares, vás para a Tessália, para junto dos hóspedes de Critão, porque lá sobeja a desordem e 
a licença, e quiçá gostariam de te ouvir contar como foi cômica a tua fuga da prisão, em travesti, metido num surrão de couro ou noutro disfarce habitual dos evadidos, e dissimulando esse jeito que é teu. Não haverá quem diga que, homem de idade, com pouco tempo provável de vida, não te pejaste de te agarres tão pegajosamente à existência, burlando as leis mais veneráveis? Talvez, se não magoares a ninguém; caso contrário, irás ouvir, Sócrates, indignidades incontáveis. Viverás de granjear o favor de toda gente, assujeitado, a fazer o quê? senão levar a vida regalada na Tessália como se lá tivesse ido para um banquete? E aquelas palestras sobre a justiça e outras formas de virtude? Por onde nos andarão elas? (Platão, s.d., 53b-54a).

Críton aceita o raciocínio de Sócrates e parte sem concretizar o plano. Mas compreende por que o filósofo aguarda com tanta serenidade o final da vida: continuará praticando a virtude, independentemente da validade ou não das acusações de que foi alvo. A cidade de Atenas pode não ter sido justa, mas agiu conforme as leis vigentes; a Sócrates, cidadão ateniense, só resta cumpri-las, caso contrário, cairá na anomia que condenou.

Não cabe discutir se o episódio é verídico ou não, se a Sócrates foi concedida a oportunidade de fugir à morte por envenenamento e se, diante dessa chance, preferiu acatar a sentença dos juízes atenienses. O fato é que, na representação de Platão, Sócrates comportou-se de modo coerente com seus princípios filosóficos e éticos, abrindo mão da vida em nome deles. Assim, atribuiu um passado ilibado a seu mestre, matéria também da Apologia, na contramão dos juízes atenienses, imagem que repercutiu na atualidade de sua atuação enquanto intelectual e na história posterior do pensamento socrático.

Platão narrou um passado, avaliou-o e transmitiu-o não apenas a seus contemporâneos, mas também aos pósteros. Discípulo de um indivíduo virtuoso e justo, embebeu-se ele mesmo da virtude e da justiça que identificou no outro, reproduzindo-as e perenizando-as. A memória de Platão converteu-se em história, erigindo uma continuidade de que ele faz parte enquanto objeto, ao beneficiar-se do exemplo do mestre e, enquanto sujeito, ao apresentar-se como emissor dos eventos ocorridos. 
Diante da hipótese de demolir um monumento, Platão buscou preservar seus alicerces, lançando-os para o futuro, do qual viemos a fazer parte.

\section{Hans Robert Jauss desmemoriado}

Identifica-se o avesso dessa situação nos episódios envolvendo a obra e a vida de Hans Robert Jauss, que, a partir dos anos 1960, liderou a vertente da crítica e da história da literatura conhecida como estética da recepção. Naquela década, ele participou do projeto educacional interdisciplinar de que resultou a Universidade de Constança, que, no período, procurou reunir a vanguarda da intelectualidade alemã, comprometida com a renovação das humanidades na República Federal. Jauss era já um pesquisador prestigiado, participante - e mesmo figurando entre os principais membros - do grupo Poetik und Hermeneutik, que, desde 1963, congregava filósofos, historiadores e teóricos da literatura, entre os quais se pode citar Hans Blumenberg, Wolfgang Iser, Karlheiz Stierle, Manfred Fuhrmann, Reinhart Koselleck - alguns dos quais também se tornaram docentes em Constança.

Romanista por formação, dedicara-se à obra de Marcel Proust em sua tese de doutoramento (Jauss, 1955). A partir da livre-docência, notabilizara-se pelas pesquisas voltadas à literatura medieval francesa, que, em suas palavras, ajudaram-no a entender os mecanismos da leitura na atualidade e a formular a metodologia da estética da recepção, fundada na noção de revitalização de textos do passado por força da resposta do leitor do presente (Jauss, 1977a; 1979a).

Os estudos que alavancaram o prestígio de Jauss foram elaborados especialmente entre 1965 e 1982, período durante o qual lançou as bases da estética da recepção enquanto projeto de renovação da história da literatura e formulou a teoria pela qual busca aproximar estética e hermenêutica, propondo uma associação entre as possibilidades de fruição catártica de obras artísticas e de, pelo mesmo gesto, entendê-las e interpretá-las. Seus livros A literatura como provocação (Jauss, 1970; 1994a) e Experiência estética e hermenêutica literária (Jauss, 1977b; 1982; Lima, 1979; 1984), sintetizam suas propostas e marcam a fase mais fértil e inovadora de sua produção. 
Ao final dos anos 1970, livros, artigos e conferências de sua autoria estão traduzidos em vários países, evidenciando o impacto de suas teses sobre as pesquisas desenvolvidas no âmbito do campo históricoliterário. Sinalizador desse impacto é a solicitação, feita pela Deutsche Forschungsgemeinschaft (Sociedade Alemã de Amparo à Pesquisa), de que refletisse sobre a situação dos estudos literários e o papel desempenhado por suas ações enquanto docente e intelectual, de que resultou o ensaio "Historia calamitatum et fortunarum mearum or: a paradigm shift in literary study", posteriormente publicado por Ralph Cohen em livro de 1989 (Olinto, 2004a; 2004b; 2015).

No referido ensaio, Jauss sintetiza sua trajetória, destacando os três objetos de sua pesquisa:

Portanto, os três principais objetos de minha pesquisa no período seguinte refletiam uma estratégia apologética: a apologia da literatura medieval, começando com um compêndio intitulado Grundriss der romanischen Literaturen des Mittelalter's (Fundamentos das literaturas românicas da Idade Média), desde 1961; a apologia da história literária, que deveria repousar sobre uma nova fundação, a chamada "Rezeptionsasthetik" (estética da recepção) como anunciado em minha aula inaugural na Universidade de Constança em 1967 e publicada como Literaturgeschichte als Provokation (A história da literatura como provocação); e finalmente (desde 1972) a apologia da experiência estética, que cresceu fora de meu envolvimento com um grupo interdisciplinar de pesquisa (Poética e Hermenêutica), fundado em 1963 (Jauss, 1989, p. 115, tradução nossa).

Mais adiante, refere-se a seu papel enquanto parte do projeto pedagógico da Universidade de Constança, calcado na interdisciplinaridade, cujo objetivo era "transferir o currículo tradicional das filologias nacionais para uma nova unidade interdisciplinar de estudo literário geral baseada no desenvolvimento da teoria, não meramente em considerações comparatistas de literatura" (Jauss, 1989, p. 123, tradução nossa). Na sequência, Jauss detém-se nas razões que levaram ao fracasso da proposta, em decorrência da negativa, por parte do Ministério (Estadual) de Cultura, que não concordou com o modelo de avaliação previsto (Jauss, 1989, p. 124), episódio também narrado em obra de 1977 (Jauss e Nesselhauf, 1977). 
Em um relato de cunho autobiográfico - acreditando-se em seu título, História de minhas desventuras e aventuras, com ênfase do pronome possessivo de primeira pessoa -, Jauss fala pouco de si mesmo. Contudo, episódios relativos ao passado de Jauss já vinham sendo objeto de notícias e de revelações, sendo a mais chocante a que dizia respeito à participação nas Waffen-SS entre 1939 e 1945. Em 1995, Earl Jeffrey Richards, então membro do corpo docente da Universidade de Münster, denuncia aqueles fatos em evento dedicado à obra do romanista Ernst Robert Curtius (Richards, 1995), autor de Literatura europeia e Idade Média latina.

O impacto das acusações levam Jauss a conceder entrevista ao filólogo francês Maurice Olender, publicada no Le Monde de 6 de setembro de 1996. Na entrevista, procura justificar por que acontecimentos de seu passado anterior e simultâneos à guerra não se tornaram públicos. Assim, perguntado sobre o que o levou a se apresentar como voluntário para as Waffen-SS em outubro de 1939 (um mês depois da rápida e vitoriosa ocupação da Polônia pelo exército alemão), Jauss responde:

$\mathrm{O}$ que me convenceu a entrar nas Waffen-SS não foi realmente a adesão à ideologia nazista. Filho de um professor, membro da pequena burguesia, eu era um jovem que queria me adaptar à atmosfera do tempo. Dito isso, eu tinha lido A decadência do Ocidente, de Spengler, escrito por um escritor banido pelos nazistas, que me deixou cético em relação ao império hitlerista. Mas, juntamente com outros futuros historiadores - penso em meus amigos Reinhart Koselleck e Arno Borst -, tínhamos em comum o desejo de não nos colocar à parte dos eventos correntes. Era preciso estar presente no campo, onde a história estava sendo feita, através da participação na guerra (Olender, 2009, p. 139-140, tradução nossa).

Jauss complementa sua resposta afirmando que "só ao final da guerra descobri o que realmente tinha acontecido - e com horror". Maurice Olender pergunta-lhe como explica por que "a maioria dos acadêmicos alemães que se comprometeram com o Nazismo calou sobre seu passado". O entrevistado divaga a respeito, levando o entrevistador a insistir: "Você pode dizer mais sobre o silêncio de uma geração?" Jauss então responde: "O silêncio neste caso está sem dúvida ligado à recusa a entender o que é inumano." Depois acrescenta: "A estranheza radical do barbarismo nazista paralisou 
uma geração de intelectuais, confinando-os à passividade, à inércia mental, literalmente à estupidez - se estupor realmente torna alguém mudo" (Olender, 2009, p. 141, tradução nossa).

Logo a seguir, discorre sobre a noção de "livre arbítrio" (Freiwilligkeit), matéria, diz ele, de seu último livro (JAUSS, 1994b) e agora objeto de relacionamento com o problema relativo à sua geração diante do nazismo:

No meu último livro, tentei falar sobre o ato de compreensão associado a "livre arbítrio" (Freiwilligkeit). De fato, não podemos chegar a uma compreensão por qualquer compulsão ou regulação, ou mesmo pelo argumento lógico: compreender algo ou alguém envolve consentimento. Devo, portanto, recusar a entender que eu não posso moralmente aprovar. Para mim, o "livre arbítrio" implicado por qualquer entendimento é o último recurso do humanismo. Com efeito, se se pode entender tudo, pode-se perdoar tudo, o que é inaceitável. Não se pode entender o genocídio cometido pelos nazistas, porque compreender seria uma forma de aprová-lo (Olender, 2009, p. 143, tradução nossa).

Maurice Olender encerra a entrevista com uma pergunta sobre a hipótese de Jauss escrever suas memórias, ideia que ele recusa, por não reconhecer, nas cartas escritas à época de suas atividades militares, o jovem que ele foi:

As cartas de minha juventude, enviadas desde o front - eu não pude relê-las por longo tempo. Quando finalmente as reli, fui pego de surpresa por um jovem que havia se tornado um estranho, a quem não poderia reconhecer como eu mesmo (Olender, 2009, p. 145, tradução nossa).

\section{0 retorno do reprimido}

Jauss faleceu em $1^{\circ}$ de março de 1997, poucos meses depois de conceder a entrevista ao Le Monde. E, por algum tempo, o assunto permaneceu latente, termo empregado por Hans Ulrich Gumbrecht, em Depois de 1945, para interpretar o comportamento da sociedade alemã, e também europeia, nas décadas subsequentes ao final da Segunda Guerra (Gumbrecht, 2014). Não permaneceu, porém, ignorado, como sugerem as reações dos leitores de Le Monde, destacando-se a matéria em que o pesquisador alemão é acusado de proceder a um "flagrante 
delito de mentira" (Schatz, 1996). Da sua parte, Earl Jeffrey Richards, em artigo de 1997, recupera a trajetória de Jauss entre 1945 e 1950, quando este teria falsificado documentos, ocultado sua vinculação com as SS e tentado fugir à justiça (Richards, 1997).

Contudo, é em 2014 que o tema, latente ou reprimido, volta à tona com intensidade. Naquele ano é encenado, no auditório da Universidade de Constança, o monólogo Die Liste der Unerwünschten (A lista dos indesejados), do dramaturgo Gerhard Zahner, a que se segue, pouco tempo depois, a apresentação pública do relatório Hans Robert Jauss: Jugend, Krieg und Internierung (Hans Robert Jauss: juventude, guerra e prisão), encomendado pelo reitor daquela instituição ao historiador Jens Westemeier. $\mathrm{O}$ documento contém minuciosa reconstrução da infância e juventude de Jauss, deixando evidente seu compromisso com a Juventude Hitlerista e o Partido Nazista:

Hans Robert Jauss era um jovem nacional-socialista e um SS convicto. A banalização da sua filiação a $S S$ com o argumento de que ainda não tinha 18 anos quando entrara na SS, ignora o entusiasmo de guerra com que os estudantes do ensino médio, desde 1933, vinham sendo politicamente motivados pela escola e pela Juventude Hitlerista. Jauss não era um simples seguidor tanto na Juventude Hitlerista quanto nas Waffen-SS. Ele participou das duas organizações nazistas de modo ativo, ocupando posições de liderança e de responsabilidade, e, enquanto líder nas Waffen-SS, foi condecorado [foi outorgada a ele a Cruz de Ouro] por seu comprometimento pessoal. Com 23 anos ele era um dos mais jovens capitães das Waffen-SS (Westemeier, 2015, p. 116, tradução nossa).

Westemeier confirma as informações fornecidas por Richards: ao se matricular, no outono de 1945, na Universidade de Bonn, Jauss apresenta documentação falsa, ao comprovar ter sido aluno da Universidade de Praga com a cópia de um atestado assinado pelo reitor daquela instituição. Datada de 1945, a declaração era atribuída a uma pessoa que se suicidara no ano anterior (Universität Konstanz, 2011).

Ao contrário de Sócrates, Jauss não foi objeto de um processo judicial, nem sujeito a qualquer pena. Mas deparou-se com o juízo de seus pares, que procuraram defendê-lo nos anos $1990,{ }^{2}$ e com o

${ }^{2}$ A propósito da reação dos colegas de Jauss, ver Oexle (1997, p. 375). 
posicionamento de um de seus mais brilhantes alunos, Hans Ulrich Gumbrecht, muitas vezes confundido com um de seus continuadores e considerado seu discípulo.

Nos vários relatos em que dá conta dos episódios relativos ao passado de Jauss e ao seu relacionamento com o orientador de tese, Gumbrecht faz questão de se desembaraçar de uma associação que, em suas palavras, não corresponde à sua trajetória intelectual e científica. Chama a atenção para a circunstância de que, desde o período de orientação, foi de certo modo levado a percorrer o próprio caminho, após ser publicamente censurado pelo mestre ao apresentar um seminário que afirmava não ter ele entendido os princípios teóricos e metodológicos da estética da recepção (Gumbrecht, 2007, p. 4-5). Em 1975, já doutor e contratado pela Universidade de Bochum, Gumbrecht escreve uma resenha sobre a estética da recepção em que expõe suas discordâncias diante das teses esposadas por Jauss (Gumbrecht, 1975). Contudo, tem consciência de que a liberação não o poupou de ser, em algumas oportunidades, confundido com o orientador:

No verão de 1977 - no hemisfério Norte era verão, de qualquer modo - regressei ao Brasil, pela primeira vez como professor convidado. Por motivos de correção política, ainda sentia alguma hesitação por estar num país em regime ditatorial. Pior ainda foi o cartaz de boas-vindas [...] que saudava o "antigo aluno" de meu tutor (Gumbrecht, 2014, p. 291).

A partir de 1990, porém, Gumbrecht deixa manifesto o esforço em se livrar dos eventuais laços que o prenderiam a Jauss. Considera exemplar o episódio em que ele, agora docente na Universidade de Stanford, na Califórnia, recusa ajuda ao ex-professor, que tivera negado o pedido de visto de entrada nos Estados Unidos em decorrência de seus precedentes laços com o nazismo:

Não faz muito tempo, no outono de 1989, Jauss escreveu-me pela última vez com a quase humilde petição de que o salvasse de uma situação desagradável na Argentina, onde, como reação à sua advertência pública a respeito da suposta ameaça de um ressurgimento no fascismo no país, alguns jornais de Buenos Aires haviam demolido a ele e ao Instituto Goethe local com a exaustiva revelação de seu passado nazi. Respondi sucintamente que somente consideraria uma intervenção desse tipo se ele me fornecesse a 
evidência factual de sua "identificação errônea", em suas palavras, como um oficial das SS. A reação de Jauss, que me chegou por fax, consistiu em três absurdamente desesperançadas palavras alemãs, Schaemen Sie sich (Você deveria se envergonhar), que resultaram ser o final (liberador, para mim) de nossa história (Gumbrecht, 2007, p. 7).

A Universidade de Constança, contudo, até então não saíra inteiramente do horizonte de Gumbrecht, que, em 1985, concorre à vaga de Jauss, aberta com a aposentadoria deste, esforço mal sucedido, conforme narrado pelo pretendente àquela posição (Gumbrecht, 2007, p. 6; 2014, p. 303).

\section{Que fazer com este legado?}

Parece não haver lugar para o réquiem de Hans Robert Jauss, pois, entre as primeiras e as últimas descobertas relativas a seu passado, transcorreram aproximadamente 20 anos, período durante o qual as acusações recrudesceram. Contudo, não se trata apenas de dessacralizar uma figura proeminente no panteão dos estudos literários, derrubando um monumento arduamente construído. A virada da fortuna sofrida pelo professor e pesquisador coloca-nos perante questões de ordem metodológica, teórica e ética, diante das quais cabe refletir e tomar posição.

A primeira questão diz respeito ao paralelo proposto entre a representação de Sócrates oferecida por um de seus discípulos, Platão, e a de Hans Robert Jauss, decorrente dos depoimentos citados. Vários fatores desaconselham a aproximação: o pensador ateniense viveu há 25 séculos, e o pesquisador alemão participou do sistema universitário europeu e ocidental entre as décadas de 1960 e 1990. Além disso, não há meios de reconstituir a trajetória de Sócrates tal como foi possível recompor o itinerário de Jauss, dada a quase inexistência de dados relativos à vida e à filosofia do ateniense, cujas ações e ideias foram registradas por seus contemporâneos, como Aristófanes, Xenofonte e Platão, não, porém, por ele mesmo. Contudo, são esses testemunhos que constroem a memória de Sócrates e restauram seu percurso na história, tanto quanto as declarações de Hans Ulrich Gumbrecht, os artigos de Earl Jeffrey Richards, o drama de Gerhard Zahner ou o relatório de Jens Westemeier substituem o Jauss histórico pelo Jauss vivenciado, imaginado ou retratado por aqueles intelectuais.

No caso de Sócrates, a balança parece pender para o filósofo, ainda que Aristófanes não perca a oportunidade de ridicularizá-lo, atitude 
exemplificada pela comédia As nuvens. A recíproca não é válida para a situação de Jauss, não por carecer de seguidores fiéis, mas, sobretudo, pelo tipo de acusação de que é vítima: a adesão ao Partido Nazista, portanto, a seu ideário, a opção pelo serviço nas $S S$, durante o período hitlerista, a falsificação do passado e o silêncio, quando se reinstalou a democracia na Alemanha Ocidental. Ter aderido ao nazismo é crime imperdoável pelo que este advogou enquanto ideologia - um modelo de exercício da autoridade e da soberania fundado no racismo, na afirmação da própria superioridade nacional, no emprego de força policial, tortura, censura e corrupção - e pelo que ocasionou: expansionismo militar, genocídio, arrogância e negação da humanidade de grandes contingentes de pessoas. No caso de Jauss, somam-se ainda as atitudes adotadas logo após o final da guerra e o comportamento ulterior diante da própria história.

As pesquisas de Earl Jeffrey Richards e de Jens Westemeier, de uma parte, os depoimentos de Hans Ulrich Gumbrecht, de outro, sugerem que o professor de Constança, desejando ou não, incorporou, em sua existência depois da derrota de Hitler e em sua prática docente, algumas marcas do nazismo, circunstância que contribui para sua condenação. A ele cabem as palavras de Daniel dirigidas ao rei da Babilônia: "Pesado foste na balança e foste achado em falta" (Daniel, capítulo 5, versículo 27).

A segunda questão refere-se, pois, às ações humanas em tempos sombrios. Sócrates foi julgado à época em que Atenas, após ter sido derrotada por Esparta na guerra do Peloponeso, submetera-se ao governo dos Trinta Tiranos e buscava restaurar a democracia. Ainda que não se possa medir o sistema político ateniense do final do século $\mathrm{V}$ e início do século IV a. C. pela régua da democracia tal como se espera que seja exercida contemporaneamente, parece evidente que o modelo que vigorou naqueles anos diferia do que a caracterizara à época de Péricles. Mesmo assim, e guardadas as proporções, a situação de Sócrates parece similar à que experimentavam intelectuais alemães desde 1933, quando Adolf Hitler, chanceler da Alemanha desde 1932, tornou-se o chefe político do Estado, com plenos poderes. Os tempos sombrios se instalavam, obrigando Hannah Arendt e Walter Benjamin, por exemplo, a exilarem-se na França em 1933, ou a Theodor W. Adorno a emigrar para a Inglaterra em 1933, depois para a América do Norte, em 1937.

O efeito desses tempos sombrios sobre Jauss só se fez sentir bem mais tarde, quando se viu na condição de perdedor e prisioneiro de 
guerra. Talvez tenha sido a nova situação que o obrigou a se reinventar, deixando que a sombra dos tempos encobrisse seu passado. $\mathrm{Na}$ sequência, e por causa disso, ele alcançou sucesso profissional em sua carreira docente, beneficiando-se com as luzes da universidade e com a prosperidade alemã que sucedeu a derrocada de Hitler.

Nesses primeiros anos, o dilema ético talvez não tenha se evidenciado para ele, já que o passado parecia esquecido. Mas, recalcado ou latente, como propõe Hans Ulrich Gumbrecht, aquele passado acabou por retornar, cobrando uma dívida que crescera com o correr dos anos, e o professor, se almejou pagá-la, não soube suprimi-la. Outra vez a ética foi vítima de uma traição, e agora em uma situação em que ela se fazia mais necessária. Afinal, se a ética é uma prerrogativa de toda a ação humana, ela se mostra com maior evidência quando se trata de intelectuais, professores e pesquisadores, especialmente quando optam por uma carreira no campo das Humanidades e exercitam-na ao formarem profissionais no âmbito da Educação.

As próximas questões derivam do dilema ético que se desenha. A primeira delas diz respeito ao legado da estética da recepção, proposta teórica e metodológica de que Hans Robert Jauss foi o principal artífice.

Ainda que Jauss, retrospectivamente, atribua às suas pesquisas sobre literatura medieval o nascimento de seu interesse pelo estudo da recepção e especialmente sobre o papel do leitor, foi o conhecimento da hermenêutica, renovada por Hans Georg Gadamer, que o conduziu aos caminhos que o notabilizaram academicamente. É em Verdade e método (Gadamer, 1979) que encontra conceitos básicos não apenas da prática da hermenêutica, mas também da historicidade de toda interpretação, razão por que importa àquele filósofo noções como as de horizonte de expectativas, fusão de horizontes, consciência da história dos efeitos, lógica da pergunta e da resposta e preconceito, formulação importante para a definição de "saber prévio", conforme a explicita em História da literatura como provocação (Jauss, 1970). De outra parte, ele busca insumos na filosofia da história, recorrendo a R. G. Collingwood (Collingwood, 1972), em cuja obra recolhe a ideia de distância histórica, decisiva para a ultrapassagem de concepções, em voga nos anos 1960, oriundas do estruturalismo de Praga, as quais igualmente incorpora, como as de distância estética, norma e valor (Mukarovski, 1977). 
A história não é irrelevante para Jauss, e é em nome dela que ergue seu edifício teórico. Em A literatura como provocação, seu estudo seminal, condena, de um lado, formalistas como Yuri Tynianov, por ignorarem fatores históricos, e, de outro, marxistas como Georg Lukács, por deixarem obras do passado circunscritas exclusivamente ao tempo de produção refletido nelas. Pela mesma razão, revitaliza o conceito de emancipação, que remonta ao pensamento de Immanuel Kant, para conferir função social à literatura, quando ela opta pela inovação e pelo experimentalismo.

Por advogar esses pressupostos teóricos, Jauss foi considerado um pensador moderno, de recorte liberal, pois privilegiava o leitor (ainda que o leitor letrado, representado pelo crítico ou pelo docente universitário) e investia na renovação dos paradigmas estéticos. Opondo-se aos nacionalismos que ainda norteiam as histórias tradicionais das literaturas, procurava valorizar o humanismo e o iluminismo, apoiado nos preceitos progressistas sugeridos pelo pensamento alemão do século XVIII (Jauss, 1973a).

Talvez Jauss tivesse efetivamente de se reinventar para abraçar valores que pareciam ir na contramão dos ideais nazistas em que fizera sua formação. Por outro lado, podemos também identificar o lado dark ou sombrio de alguns de seus posicionamentos, como a rejeição da noção de negatividade, exposta por Theodor W. Adorno (Adorno, 1974) em Teoria estética (Jauss, 1982).

Seria, sem dúvida, redutor e irresponsável acusá-lo de antissemita por não concordar com pensadores judeus, e tanto é assim que Jauss assume também posição contrária a que Roland Barthes expõe em O prazer do texto (Jauss, 1979b). Contudo, desde a Dialética do esclarecimento (Adorno, Horkheimer, 1946/1985), Adorno é o crítico de ponta do Iluminismo, identificando neste o culto à razão utilitária e à tecnologia, atitudes e concepções que justificaram a barbárie expressa na política e na moral do Terceiro Reich. O posicionamento radical de Adorno deve ter incomodado o jovem Jauss, que só atacou aquele professor após sua morte, que se seguira a seu desprestígio junto aos estudantes em vista de suas decisões diante da invasão da Universidade de Frankfurt, em 1969.

Adorno não chegou a ser um dos monumentos que veio abaixo após a alteração das vogas estéticas. Em decorrência de seu temperamento amargo - como sugerem seus textos e os debates que o opuseram a Walter Benjamin (Adorno, 1980a, p. 110), antes da guerra e, depois dessa, a Sartre e a Brecht (Adorno, 1980b, p. 177) -, Adorno foi lido, suas 
ideias, repetidas, considerado líder de uma linhagem filosófica (a Teoria Crítica, também conhecida como Escola de Frankfurt), mas nunca amado. Por outro lado, não foi acusado de se beneficiar de qualquer regime autoritário, responsável por perseguições étnicas, massacre de pessoas e ambições totalitárias.

Jauss, como Adorno, não foi idolatrado como Walter Benjamin, ainda que esse fato tenha ocorrido postumamente. Mas não deixou de se elevar como um monumento, quando associou a história da Universidade de Constança à sua trajetória intelectual e acadêmica. Poderia ter optado por um perfil mais discreto, mas não o fez. Talvez tenha almejado construir uma memória que apagasse outras lembranças, mas acabou vítima do passado não apenas por tê-lo vivido, mas por ter procurado ignorá-lo. Para Earl Jeffrey Richards, Jauss "deveria ter indubitavelmente vivido com essa contradição entre o oficial das SS e o professor da República Federal Alemã", por isso, complementa, "dele deveríamos esperar mais do que um simples silêncio" (Richards, 1997, p. 12-13, tradução nossa).

Colocado em outros termos, o emérito professor da Universidade de Constança foi obrigado a provar do próprio veneno, ao ser atropelado pela "história dos efeitos" que faz a narração dos eventos transcorridos. O passado repercutiu no presente e cobrou a conta, mas o capital ético de Jauss não bastou para saldar a dívida. Por isso, ao contrário de Sócrates, não dispôs de advogados de defesa, vendo-se ele mesmo na situação de se justificar e ter de, mais uma vez, elaborar uma narrativa que minimizasse os fatos ocorridos.

A última questão é provavelmente a mais relevante: devemos - ou devo, na condição de autora de livro e artigos sobre estética da recepção (Zilberman, 1989; Zilberman, 2014) - voltar as costas para Jauss e fingir não conhecê-lo? Hans Ulrich Gumbrecht, que foi seu aluno, procurou, conforme suas palavras, descolar-se do professor desde o começo de sua trajetória acadêmica, quando assumiu, em 1975, um posto na Universidade de Bochum. Recentemente, em entrevista a Siegmund Kopitzki, declarou que "nunca ser[á] grato a ele" (Gumbrecht, 2016, s.p., tradução nossa), reportando mais uma vez à sua trajetória, relatada também em Depois de 1945. Em polo oposto, José Guilherme Merquior, em Arte e sociedade em Marcuse, Adorno e Benjamin, procura abrandar as ligações de Martin Heidegger com o Partido Nazista (Merquior, 1969, p. 203), posição não muito distinta da que, recentemente, Gumbrecht adotou (Gumbrecht, 2014, 
p. 307). Ottmar Ette, professor da Universidade de Potsdam e autor de Der Fall Jauss: Wege des Verstehens in eine Zukunft der Philologie (Ette, 2016), livro recentemente lançado, examina a questão desde a perspectiva dos estudos acadêmicos no âmbito da romanística e da teoria da literatura: "A exclusão de Jauss da história da romanística, bem como da ciência da literatura do século $\mathrm{XX}$, prejudica, de toda a maneira, os caminhos na filologia no futuro" (Ette, 2016, p. 25, tradução nossa).

Não se pode deixar de reconhecer a importância do projeto de uma nova história da literatura, tal como Jauss propõe em sua conferência, depois transformada em livro, proposição aplicada por ele em alguns de seus ensaios, como os dedicados às tragédias intituladas Ifigênia, respectivamente de Eurípedes, Racine e Goethe (Jauss, 1973a), ou à poesia francesa publicada em 1857, contemporânea, pois, ao lançamento de As flores do mal, de Baudelaire (Jauss, 1975). Nos anos 1960, à época em que Jauss formulou a crítica à estagnação da história da literatura tal como praticada no ensino e apresentou alternativas inovadoras de pesquisa, aquela área de conhecimento vinha sendo efetivamente marginalizada em decorrência dos avanços metodológicos e teóricos fomentados pelo estruturalismo. $\mathrm{O}$ empenho que expressou em seus escritos fecundou não apenas sua atuação acadêmica mas também a de uma geração, que buscou os efeitos da recepção sobre a criação artística e, especialmente, sobre a circulação da literatura na sociedade.

Depois disso, o pesquisador progrediu pouco, optando então por valorizar os processos de conhecimento da obra literária desde o conceito de experiência estética. Enquanto isso, as áreas que escolhera, história e história da literatura, prosperavam graças às investigações vinculadas à história das ideias (Foucault, 2009; 2011), à sociologia da leitura (Engelsing, 1974; Schenda, 1976; 1977; Leenhardt, 1980; Dann, 1981) e à história do livro e da leitura (Chartier, 1987; Darnton, 1982; 1986).

De outra parte, Jauss introduziu nos estudos literários um conceito que não pode ser ignorado - o de emancipação, que foi buscar entre os iluministas para integrá-lo a uma concepção de fazer literário enquanto liberação, experimentado tanto pelo criador quanto pelo leitor. Reconhecida a pertinência daquele conceito, por um lado, por outro, é possível voltá-lo contra o próprio Jauss, pois, formado dentro do espírito de suas teses estético-recepcionais, é dessa metodologia e, sobretudo, do sujeito que as enunciou que talvez seja necessário libertar-nos. Hans Ulrich Gumbrecht confessa que experimenta essa 
situação permanentemente e a "hermenêutica edípica" a que se refere no estudo que tem esse título (Gumbrecht, 2007). E também, em Depois de 1945, evidencia que a ruptura ainda não se completou.

A possibilidade ou não superar a contradição que Gumbrecht reconhece é uma alternativa que se apresenta enquanto horizonte, não de expectativas passadas ou presentes, mas futuras. De todo modo, diante de uma personalidade que parece não ter se orientado pela virtude ou pelo dever, não é aceitável ser tão pouco ético quanto ele. A lição de Sócrates, conforme a relata Platão, é ilustrativa: é melhor buscar pautar-se pela justiça, do que abraçar a injustiça, quando nos deparamos com o erro ou o delito.

Mesmo que, em tempos sombrios, indivíduos possam não ter sido tão iluminados quanto almejou Hannah Arendt, suas trajetórias esboçam caminhos que, menos ou mais éticos, suscitam, de uma parte, nossa reflexão, de outra, nossas opções.

\section{Referências}

ADORNO, Theodor W. (1974). Théorie esthétique. Tradução de Marc Jimenez. Paris: Klincksieck.

ADORNO, Theodor W. (1980a). Letters to Walter Benjamin. In: BLOCH, Ernst et al. Aesthetics and politics. Londres: Verso.

ADORNO, Theodor W. (1980b). Commitment. In: BLOCH, Ernst et al. Aesthetics and politics. Londres: Verso.

ADORNO, Theodor W.; HORKHEIMER, Max (1946/1985). Dialética do esclarecimento: fragmentos filosóficos. Tradução de Guido Antonio de Almeida. Rio de Janeiro: Zahar.

ARENDT, Hannah (2008). Homens em tempos sombrios. Tradução de Denise Bottmann. São Paulo: Companhia das Letras.

BRECHT, Berthold (2011). À posteridade. Tradução de Mario Faustino. Tim Tim no Tibet. [S.l.]: [S.n.], 19 mar. On-line. Disponível em: <https://goo.gl/jeJ7ji>. Acesso em: 19 ago. 2016.

CHARTIER, Roger (1987). Lectures et lecteurs dans la France d'Ancien Régime. Paris: Seuil. COLLINGWOOD, Robin G. (1972). A ideia de história. Lisboa: Presença. 
DANIEL. (S.d.). In: Bíblia sagrada. Tradução de João Ferreira de Almeida. Barueri: Sociedade Bíblica do Brasil.

DANN, Otto (Hrsg.) (1981). Lesegesellschaften und Bürgelische Emanzipation. Ein europäischen Vergleich. München: Beck.

DARNTON, Robert (1982). The literary underground of the Old Régime. Cambridge: Harvard University Press.

DARNTON, Robert (1986). The Great Cat Massacre and other episodes in French cultural history. New York: Vintage Books, 1985.

ENGELSING, Rolf (1974). Der Bürger als Leser. Lesergeschichte in Deutschland 1500-1800. Stuttgart: J. B. Metzlersche Verlagsbuchhandlung.

ETTE, Ottmar (2016a). Der Fall Jauss. Wege des Verstehens in eine Zukunft der Philologie. Berlim: Kulturverlag Kadmos.

ETTE, Ottmar (2016b). Ein hermeutischer Fall. Jauss und die Zukunft der Romanistik. Zeitschrift für Ideengeschichte, München, v. 11, n. 3, p. 118-126.

FOUCAULT, Michel (2009). História da loucura na Idade Clásssica. Tradução de José Teixeira Coelho Netto. São Paulo: Perspectiva.

FOUCAULT, Michel (2011). O nascimento da clínica. Tradução de Roberto Machado. Rio de Janeiro: Forense Universitária.

GADAMER, Hans Georg (1979). Verdad y metodo. Fundamentos de una hermenéutica filosófica. Tradução de Ana Aguf Aparicio e Rafael de Agapito. Salamanca: Sígueme.

GUMBRECHT, Hans Ulrich (1975). Konsequenzen der Rezeptionsaesthetik oder Literaturwissenschaft als Kommunikationssoziologie. Poética 7, p. 388-415.

GUMBRECHT, Hans Ulrich (2007). De la hermenéutica edípica a la filosofía de la presencia, Fractal, México, ano 12, v. 12, n. 47, p. 15-40, oct./dic.

GUMBRECHT, Hans Ulrich (2014). Depois de 1945. Latência como origem do presente. Tradução de Ana Isabel Soares. São Paulo: Unesp.

GUMBRECHT, Hans Ulrich (2016). Ich will ihm nicht dankbar sein. Interview mit Siegmund Kopitzki. Südkurier, Konstanz, Kultur, 6 jun. On-line. Disponível em: <https://goo.gl/9CIkJT>. Acesso em: 20 ago. 2016.

JAUSS, Hans Robert (1955). Zeit und Erinnerung in Marcel Prousts "À la recherche du temps perdu": ein Beitrag zur Theorie des Romans. Heidelberg: Carl Winter Universitaet Verlag.

JAUSS, Hans Robert (1970). Literaturgeschichte als Provokation. Frankfurt: Suhrkamp. 
JAUSS, Hans Robert (1973a). Racines und Goethe Iphigenie. Mit einem Nachwort über die Partialität der rezeptionsästhetischen Methode. Göttingen: Vandenhoeck \& Ruprecht, p. 1-46. (Neue Hefte für Philosophie, 4)

JAUSS, Hans Robert (1973b). Geschichte der Kunst und Historie. In: KOSELLECK, Reinhardt; STEMPEL, Wolf-Dieter (Ed.). Geschichte - Ereignis und Erzählung. München: Fink.

JAUSS, Hans Robert (1975). La douceur du foyer - Lyrik des Jahres 1857 als Muster der Vermittlung sozialer Normen. In: WARNING, Rainer. Rezeptionsästhetik. München: Fink.

JAUSS, Hans Robert (1977a). Littérature médiévale et expérience esthetique. Actualité des questions de littérature de Robert Guiette. Paris: Seuil. (Poétique, 31).

JAUSS, Hans Robert (1977b). Ästhetische Erfahrung und literarische Hermeneutik. Frankfurt: Suhrkamp.

JAUSS, Hans Robert (1979a). The alterity and modernity of medieval literature. New Literary History, Charlottesville, University of Virginia, v. 10, n. 2.

JAUSS, Hans Robert (1979b). O prazer estético e as experiências fundamentais da poiesis, aisthesis e katharsis. In: LIMA, Luiz Costa (Org.) A literatura e o leitor. Rio de Janeiro: Paz e Terra.

JAUSS, Hans Robert (1982). Aesthetic experience and literary hermeneutics. Minneapolis: University of Minnesota Press.

JAUSS, Hans Robert (1989). Historia calamitatum et fortunarum mearum or: a paradigm shift in literary study. In: COHEN, Ralph (Ed). The future of literary theory. New York and London: Routledge.

JAUSS, Hans Robert (1994a). A história da literatura como provocação da ciência literária. Tradução de Sérgio Tellaroli. São Paulo: Ática.

JAUSS, Hans Robert (1994b). Wege des Verstehens. München: Fink.

Jauss, Hans Robert; Nesselhauf, Herbert (Ed.) (1977). Gebremste Reform: Ein Kapitel deutscher Hochschulgeschichite. Universität Konstanz 1966-1976. Konstanz: Universitätsverlag Konstanz GMBH.

LEENHARDT, Jacques (1980). Towards a sociology of reading. In: SULEIMAN, Susan; CROSMAN, Inge (Org.) The reader in the text. Essays on audience and interpretation. Princeton: Princeton University Press.

LIMA, Luiz Costa (Org.) (1979). A literatura e o leitor. Rio de Janeiro: Paz e Terra.

LIMA, Luiz Costa (Org.) (1984). Teoria da literatura em suas fontes. 2. ed. Rio de Janeiro: Francisco Alves, v. 2. 
MERQUIOR, José Guilherme (1969). Arte e sociedade em Marcuse, Adorno e Benjamin. Ensaio crítico sobre a escola neo-hegeliana de Frankfurt. Rio de Janeiro: Tempo Brasileiro.

MUKAROVSKI, Jan (1977). Escritos de estética y semiótica del arte. Tradução de Anna Anthony-Visova. Barcelona: Gustavo Gili.

OEXLE, Otto Gerhard (1997). Zweierlei Kultur. Zur Erinnerungskultur deutscher Geistes-wissenschaftler nach 1945. Rechtshistorisches Journal, n. 16, p. 358-390.

OLENDER, Maurice (1996/2009). The radical strangeness of Nazi barbarism has paralyzed a generation of intellectuals: dialogue with H. R. Jauss. In: OLENDER, Maurice. Race and erudition. Cambridge: Harvard University Press, p. 139-145. Disponível em: <https://goo.gl/knBuvS>. Acesso em: 12 ago. 2016.

OLINTO, Heidrun Krieger (2004a). Intelectuais no universo de letras. Gragoatá, Niterói, n. 17, p. 131-150, $2^{\circ}$ sem. Disponível em: <https://goo.gl/eYbnv3>. Acesso em: 13 ago. 2016.

OLINTO, Heidrun Krieger (2004b). Questões institucionais no sistema literário. Revista de Letras, São Paulo, v. 44, n. 1, p. 47-67. Disponível em <https://goo.gl/kXIUsv>. Acesso em: 13 ago. 2016.

OLINTO, Heidrun Krieger (2015). Relatos autobiográficos desfocados. Red, Rio de Janeiro, n. 1. Disponível em <https://goo.gl/JEK1tf>. Acesso em: 13 ago. 2016.

PLATÃO (s.d.). Critão (Críton), ou o Dever. In: PLATÃO. Diálogos. Tradução de Jaime Bruna. São Paulo: Cultrix. (Coleção Clássicos). Disponível em: <https://goo.gl/02hYIG>. Acesso em: 10 jul. 2016.

RICHARDS, Earl Jeffrey (1995). La conscience européenne chez Curtius et chez ses détracteurs. In: BEM, Jeanne; Guyaux, André (Org.). Ernst Robert Curtius et l'idée d'Europe. Actes du Colloque de Mulhouse et Thann. Paris: Honoré Champion.

RICHARDS, Earl Jeffrey (1997). Vergangenheitsbewaltigung nach dem Kalten Krieg. Der Fall Hans Robert Jauss und das Verstehen. Germanisten. Zeitschrift schwedischer Germanisten, n. 1, p. 1-15.

SCHATZ, Jacques (1996). Les "mensonges" de Hans Robert Jauss. Le Monde, 15 set. On-line. Disponível em: <https://goo.gl/IVhD6i>. Acesso em: 13 ago. 2016.

SCHENDA, Rudolf (1976). Die Lesestoffe der kleinen Leute. Studien zur populären Literatur im 19. und 20. Jahrhundert. München: Beck.

SCHENDA, Rudolf (1977). Volk ohne Buch. Studien zur Sozialgeschichte der populären Lesestoffe. München: DTV. 
UNIVERSITÄT KONSTANZ (2011). Reinigung des Bestands der Buchbereiche $G$ und $S$ der Bibliothek der Universität Konstanz beginnt. Presseinformation, Konstanz, v. 20, n. 48, Jan. Disponível em: <https://goo.gl/vW98oS>. Acesso em: 13 ago. 2016.

WESTEMEIER, Jens (2015). Hans Robert Jauss: Jugend, Krieg und Internierung. Konstanz: Universitäet Konstanz.

ZILBERMAN, Regina (1989). Estética da recepção e história da literatura. São Paulo: Ática. ZILBERMAN, Regina (2014). Estética da recepção. In: CITELLI, Adilson et al. (Org.). Dicionário de comunicação: escolas, teorias e autores. São Paulo: Contexto.

Recebido em 11 de novembro de 2016.

Aprovado em 14 de abril de 2017.

\section{resumo/abstract/resumen}

\section{Memórias de tempos sombrios}

Regina Zilberman

Nos anos 1960, Hans Robert Jauss propôs a renovação da história da literatura, a ser formulada desde a perspectiva do leitor, o que impulsionou a corrente teórica que denominou estética da recepção. Na década seguinte, dedicou-se ao estudo das relações entre interpretação hermenêutica e experiência estética. Nos anos 1990, foi revelado seu passado nazista, sendo que, em 2014, foram adicionadas novas informações sobre suas ações durante e depois da guerra. Considerando essas descobertas, que posição aquele pesquisador passa a ocupar no campo intelectual? Em que medida continuam válidas suas teses? Em que situação - ética e científica - ficam os que, como a autora deste artigo, adotaram conceitos e métodos de investigação sugeridos por Hans Robert Jauss?

Palavras-chave: Jauss, estética da recepção, nazismo.

\section{Memories of dark times}

Regina Zilberman

In the 1960s, Hans Robert Jauss proposed the renewal of literary history, which was to be built from the reader's perspective. He thus energized the theoretical movement called aesthetics of reception. In the following decade, 
Jauss turned to the study of relations between hermeneutic interpretation and aesthetic experience. In the 1990s, his Nazi past was disclosed, and in 2014 new information about his actions during and after the war were revealed. Considering these findings, this article asks what position does Jauss occupy in the intellectual field? To what extent are his theses still valid? What is the position - ethical and scientific - of researchers who, like the author of this article, adopted concepts and methods suggested by Hans Robert Jauss?

Keywords: Jauss, aesthetics of reception, Nazism.

\section{Memorias de tiempos sombrios}

Regina Zilberman

En la década de 1960, Hans Robert Jauss propuso la renovación de la historia de la literatura, a formularse desde la perspectiva del lector, lo que impulsó la corriente teórica llamada estética de la recepción. En la década siguiente, Jauss se dedicó al estudio de las relaciones entre la interpretación hermenéutica y la experiencia estética. En la década de 1990, se reveló su pasado nazi, y en 2014 se añadieron nuevas informaciones acerca de sus acciones durante y después de la guerra. Teniendo en cuenta estas evidencias, ¿cuál es la posición que Jauss ocupa ahora en el campo intelectual? ¿En qué medida siguen siendo válidas sus tesis? ¿En qué situación - ética y científica - están aquellos que, como el autor de este artículo, adoptaron conceptos y métodos de investigación sugerido por Hans Robert Jauss?

Palabras clave: Jauss, estética de la recepción, nazismo. 